\title{
Allen E. Richardson, Seeing Krishna in America. The Hindu Bhakti Tradition of Vallabhacharya in India and its Movement to the West
}

Jefferson, North Carolina, McFarland \& Company Inc. Publishers, 2014, $240 \mathrm{p}$.

Glossaire, appendices, notes, bibliographie, index.

Catherine Clémentin-Ojha

\section{(2) OpenEdition}

Journals

Édition électronique

URL : http://journals.openedition.org/assr/27449

DOI : 10.4000/assr.27449

ISSN : $1777-5825$

Éditeur

Éditions de l'EHESS

Édition imprimée

Date de publication : 1 octobre 2015

Pagination : 360

ISBN : 978-2-7132-2515-4

ISSN : 0335-5985

Référence électronique

Catherine Clémentin-Ojha, « Allen E. Richardson, Seeing Krishna in America. The Hindu Bhakti Tradition of Vallabhacharya in India and its Movement to the West », Archives de sciences sociales des religions [En ligne], 172 | octobre-décembre, mis en ligne le 09 juin 2016, consulté le 24 septembre 2020. URL : http://journals.openedition.org/assr/27449; DOI : https://doi.org/10.4000/assr.27449

Ce document a été généré automatiquement le 24 septembre 2020.

(C) Archives de sciences sociales des religions 


\section{Allen E. Richardson, Seeing Krishna in America. The Hindu Bhakti Tradition of Vallabhacharya in India and its Movement to the West}

Jefferson, North Carolina, McFarland \& Company Inc. Publishers, 2014, $240 \mathrm{p}$.

Glossaire, appendices, notes, bibliographie, index.

Catherine Clémentin-Ojha

\section{RÉFÉRENCE}

Allen E. Richardson, Seeing Krishna in America. The Hindu Bhakti Tradition of Vallabhacharya in India and its Movement to the West, Jefferson, North Carolina, McFarland \& Company Inc. Publishers, 2014, 240 p.

Glossaire, appendices, notes, bibliographie, index. 
1 Fondée en Inde du Nord à l'extrême fin du $\mathrm{XV}^{\mathrm{e}}$ siècle par Vallabhācārya (1470-1532), théologien brahmane originaire $d u$ Telangana (Inde du Sud), la communauté religieuse étudiée dans cet ouvrage s'organise autour du culte de Kṛ̣nạ, l'un des avatāra de Viṣnu. Elle est bien connue en Inde pour la manière fastueuse dont elle célèbre le jeune dieu espiègle, dont le Bhāgavata-purāṇa (vers le $\mathrm{x}^{\mathrm{e}}$ siècle) raconte la geste, et pour le style de vie opulent de ses gosvāmī («maîtres des vaches») qui se partagent sa direction. Tous descendants directs de Vallabha, les gosvāmī se rattachent à sept sièges (gaddī) principaux installés pour la plupart au Rajasthan, à l'ouest de la terre krishnaïte $\mathrm{du}$ Braj, berceau d'origine de la secte. Leurs disciples appartiennent en grande

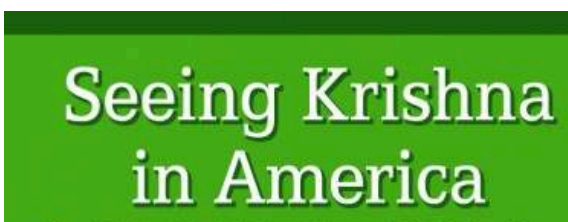

The Hindu Bhakti Tradition of Vallabhacharya in India and Its Movement to the West

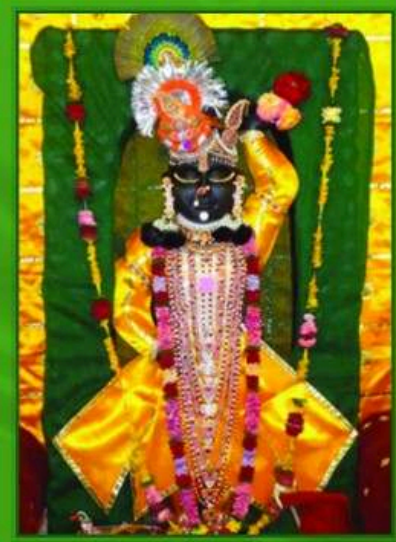

E. Allen Richardson majorité à des castes marchandes du Gujarat, adonnées de longue date au commerce dans ce pays côtier. Les plus dynamiques d'entre eux sont aujourd'hui à la tête de puissantes dynasties capitalistes.

2 Les différentes communautés de croyants, toutes désignées sous la même expression de " secte hindoue ", sont autant de formes d'appartenance à l'hindouisme. Elles dessinent au sein de celui-ci des voies de libération initiatiques reposant sur des formes distinctes de théisme (bhakti), les unes centrées sur le culte de Viṣnu sous l'un ou l'autre de ses avatāra, les autres sur celui de Śiva. La secte de Vallabhācārya ou pușțimārga (« voie de la grâce ») appartient au sous-ensemble des sectes vishnouites dites krishnaïtes parce qu'elles considèrent que la libération spirituelle passe par Kṛ̣ṇa et par lui seul.

3 Toute secte, comme l'enseignent les sociologues, est un appareil de sélection qui sépare les personnes qualifiées des autres. Si aujourd'hui la plupart des puștimārgīya naissent dans la secte, logique sectaire oblige, il faut recevoir l'initiation d'un des gosvāmī pour avoir droit à l'enseignement théologique de Vallabhācārya (une lecture théiste des textes du vedānta - upaniṣad et Bhagavad-Gìtā - consignée dans de savants traités en sanskrit) et être admis au culte. Comme membre de la famille de Vallabhācārya, chaque gosvāmì exerce sur ses disciples une autorité incontestable dans le domaine spirituel. Ceux qui assurent la direction de l'un des sept sièges tirent une légitimité supplémentaire de leur possession héréditaire d'un svarūpa («forme propre »), image divine particulièrement puissante puisque considérée comme une manifestation de Kṛ̣ṇa lui-même. Mais dûment consacrées, d'autres images, de mains d'hommes celleslà, permettent aux puștimārgìya de faire le darśana de Kṛ̣ṇa, c'est-à-dire le voir et se faire voir de lui. Aujourd'hui de telles images ont été installées sur le sol américain. Elles y sont arrivées avec des commerçants et hommes d'affaires puștimārgìya qui, profitant de la réforme des lois d'immigration (1965), ont commencé à immigrer aux États-Unis au début des années 1970. L'ouvrage de Richardson traite de ce phénomène. 
4 De nombreux travaux ont déjà été consacrés à la secte de Vallabhācārya en Inde. Il existe aussi une importante bibliographie sur les organisations religieuses hindoues présentes aux États-Unis (pour une bonne introduction, voir «Hinduism in America » par Vasudha Narayan, Edwin F. Bryant, Diana Eck et Prema Kurien dans Laderman, Gary \& Leon, Luis D., ed., Religion and American Cultures. An Encyclopaedia of Traditions, vol. 1, Santa, California, ABC-CLIO, Inc., 2003, p. 99-122). Américaniste et spécialiste de la construction de l'identité américaine en contexte de pluralité ethnique et culturelle (Strangers in this land: pluralism and the response to diversity in the United States, New York, McFarland Press, 2009 [ $1^{\text {re }}$ édition 1988]), Richardson tire le meilleur parti de ces études pour examiner le processus de transplantation du pușțimārga en Amérique, en mettant en lumière les spécificités religieuses de la secte migrante comme celles de la terre d'accueil. Quoiqu'il traite rapidement certaines notions religieuses complexes et propose une transcription peu académique des termes sanskrits, son ouvrage démontre l'intérêt qu'il y a à mettre le transfert de la secte aux États-Unis dans une perspective qui tienne compte de son histoire en Inde. Son projet, clairement affiché, étant d'expliquer la religion de Vallabhācārya au lectorat américain, il commence par lui fournir ce qu'il estime être les clés indispensables pour la comprendre dans son contexte indien (chap. 1-4), puis il lui donne sur l'adaptation des expatriés puștimārgìya aux conditions nord-américaines des informations de première main qu'il a recueillies au cours d'une enquête approfondie (chap. 5-7).

5 De son histoire en Inde, on peut surtout retenir la capacité de la secte de Vallabhācārya à étendre sa sphère d'action tout en construisant sa cohésion. Comme toute secte théiste hindoue, elle est essentiellement prosélyte et missionnaire. Toutefois le déplacement géographique semble plus particulièrement inscrit dans ses gènes puisque son fondateur, brahmane du Sud, choisit de l'implanter dans le très lointain nord, en terre krishnaïte. Quelques décennies plus tard, les intenses rivalités entre les héritiers de Vallabhācārya conduisent les cadets des sept principaux sièges à fonder de nouvelles lignées et à rechercher des patronages plus lointains dans un contexte d'instabilité politique et de compétition sectaire. La mobilité de la secte tient aussi aux activités marchandes de ses disciples qui, voulant voir Krishna partout où ils commercent, financent de nouveaux temples. C'est ainsi que dans les deux premiers siècles de l'existence de la secte, les gosvāmī conquièrent de nouveaux espaces régionaux, en recrutant principalement parmi les riches castes mercantiles du Gujarat et du Rajasthan. Mais la logique hiérarchique de la société hindoue explique que le pușțimārga finisse par se confondre avec ces dernières pour former une communauté soudée autour de leurs valeurs. En dépit des principes qu'elle affiche, en effet, aucune secte hindoue ne peut ignorer les règles d'évitement de la société des castes qui s'imposent à ses membres. Ainsi, tandis que l'autonomie de ses lignées et leurs rivalités incessantes pour obtenir les meilleurs patronages ont permis au puștimārga de prospérer hors du Braj et de s'implanter dans l'Inde du Nord-ouest, son recrutement homogène (un petit nombre de castes marchandes de même statut) a assuré sa cohésion sociale, culturelle et religieuse. Ces deux phénomènes expliquent l'identité actuelle de la secte et une partie de sa réussite aux États-Unis. La secte de Vallabhācārya est une religion de marchands gujarati. C'est le lien étroit, sinon l'exacte congruence, entre région, langue, caste et secte, qui lui ont permis, une fois transplantée aux États-Unis, d'adopter sans trop de difficulté le mode de gestion américain de la pluralité religieuse. 
6 A aussi contribué à la cohésion de la secte la standardisation de sa principale pratique religieuse : faire le darśana de Kṛṣna, le voir comme en être vu. Chacune des sept principales lignées organise le culte (sevā) de son svarūpa selon la même liturgie extrêmement élaborée, qui se reproduit huit fois dans une même journée à un rythme régulier. Parce que présence réelle, tout svarūpa est choyé de diverses manières : il est richement vêtu, décoré de bijoux, nourri de mets délicats uniquement végétariens, et installé dans une demeure cossue (havelī), qui est aussi celle de son gosvāmī, son premier serviteur, et non dans un temple comme les autres images divines hindoues. Avides de faire son darshana, les disciples se pressent frénétiquement pendant le culte, seul moment où le rideau qui leur dissimule l'image est tiré. Ils consomment ensuite l'offrande de nourriture consacrée ou prasāda (grâce). Richardson a su trouver les arguments et mots justes pour faire ressentir à son lecteur l'intensité de la relation émotionnelle qui se construit dans ce face à face répété avec une image divine, qui toujours se dérobe à la vue de ses adorateurs.

7 La cohésion de la communauté des puștimārgīya tient aussi qu'à ces rites célébrés par des prêtres dans les haveli, s'ajoutent des rites personnels, qui rappellent l'appartenance sectaire jusque dans la sphère domestique. Chaque famille possède une image consacrée (non auto-manifestée) de Kṛṣna, à laquelle elle rend un culte quotidien. Cette pratique implique l'observance d'un régime alimentaire particulier puisque jusque chez eux les puștimārgìya ont l'obligation de se nourrir uniquement du prasāda de Kṛșna. La petite taille des images divines facilite leur transport lorsque la famille doit voyager, qu'il s'agisse de se déplacer pour faire le darshana des sept svarūpa ou celui des nombreux baithaka. Ces stations qui parsèment le territoire indien marquent les lieux où Vallabhācārya, très mobile lui-même on l'a compris, se serait arrêté au cours de ses trois grands tours en Inde. Au cours de leur histoire, les pușt imārgìya se sont pliés d'autant plus volontiers à ces déplacements religieux que chez eux, réseaux marchands et réseaux de pèlerinage se confondaient.

8 Le svarūpa le plus éminent, dont tout pușțimārgìya veut faire le darśana et consommer le prasāda, est celui de Śrīnāthajī, forme auto-manifestée de Kṛṣna miraculeusement découverte par Vallabhācārya lui-même au Braj. C'est une divinité voyageuse, bien adaptée à la nature mobile de ses dévots marchands. Après avoir profité au pays Braj du généreux patronage de l'empire moghol (musulman), Śrīnāthajī a en effet quitté sa terre natale quand la situation politique y est devenue instable pour se mettre sous la protection de la dynastie rajpoute (hindoue) du Mewar (Udaipur, Rajasthan). Il réside depuis à Nathdwara (au nord d'Udaipur) dans une splendide havelī. Mais désormais on peut aussi faire son darśana aux États-Unis. Non que le célèbre svarūpa se trouve sur le sol américain : c'est symboliquement que cette fois il a fait le voyage car c'est à sa semblance que sont fabriquées la plupart des images divines qui, une fois rituellement animées, y ont été installées.

9 Plutôt qu'à "voir Kṛșṇa », c'est donc principalement à "voir Śrīnāthajī » que se consacrent les pușțimārgìya expatriés en Amérique du Nord. C'est d'ailleurs ce que montre clairement la couverture du livre qui représente la réplique du célèbre svarūpa installée dans le Vraj Temple en Pennsylvanie, centre de la secte aux États-Unis. Cette focalisation sur Śrīnāthajī projette le gosvāmī de Nathdwara sur le devant de la scène pu știmārgìya alors qu'on n'observe rien de tel en Inde. Même s'il retire de la possession de Śrīnāthajī une aura spirituelle qui se traduit par un indéniable prestige social, il n'est pas le chef de la secte et n'a aucun droit de regard sur les six autres sièges. Le succès du 
culte de Śrīnāthajī aux États-Unis ne va donc pas sans perpétuer une certaine rivalité intrasectaire. Richardson la laisse apercevoir mais on aurait aimé qu'il s'y arrête davantage. Toutefois il faut garder à l'esprit que le culte de Śrīnāthajī ne serait pas arrivé aux États-Unis si les laïcs puștimārgīya expatriés ne l'y avaient fait venir. Ce sont eux qui ont joué un rôle de premier plan dans la fondation de temples aux États-Unis à partir des années 1970. Pour bien le comprendre il faut préciser qu'alors, cela fait plusieurs décennies que les puștimārgìya ont pris en mains les affaires de leurs havelī en Inde même. Et ce fait doit lui-même être replacé dans le cadre de la politique religieuse que les Britanniques mènent en Inde à l'époque coloniale.

10 À partir de la seconde moitié du XIX ${ }^{e}$ siècle, la secte de Vallabhācārya subit en effet un certain nombre de réformes dans l'administration de ses temples. On peut regretter que Richardson se contente d'évoquer rapidement les transformations qui en résultent, alors qu'il consacre de nombreuses pages au patronage royal dont la secte bénéficie depuis sa fondation jusqu'aux premières décennies du xIX ${ }^{e}$ siècle, tant de la part des Moghols dans ses premières décennies que de celle des Rajpouts à la période suivante. Or, pour bien comprendre le devenir actuel de la secte, il aurait fallu regarder de plus près ce qui s'est passé après l'effondrement du système de patronage dans lequel les gosvāmī étaient passés maîtres. En fait Richardson reste trop discret sur les déboires que connaissent ces derniers du temps où les Britanniques apportent de nouvelles définitions du licite et de l'illicite en matière religieuse. Comme nombre de travaux le montrent, les gosvāmī font l'objet de vives critiques de la part de divers réformateurs et surtout de celle de leurs propres disciples, qui mettent en doute leur moralité et réclament davantage de transparence dans leur gestion des biens des temples. Tout cela explique que la secte connaisse un mouvement de « laïcisation » : ses disciples laïcs prennent une place plus importante dans son administration. Avec le départ des Britanniques (1947), la situation personnelle des gosvāmī s'aggrave encore: non seulement ils perdent toute forme de patronage royal après l'intégration des monarchies dans la République indienne, mais leurs finances et propriétés foncières sont placées sous strict contrôle étatique par la nouvelle nation qui s'est donné une constitution laïque. Ces développements conduisent les disciples de la secte, hommes d'affaires avertis pour la plupart, à s'impliquer davantage dans la gestion de ses finances.

11 L'intéressante enquête conduite en Inde par Richardson montre que, aujourd'hui, une bonne part de la réussite économique des puștimārgìya est liée au développement de l'industrie touristique. On ne s'étonnera pas que des puștimārgìya excellent dans cette version modernisée du pèlerinage, pratique fondamentale pour eux comme on l'a vu, $\mathrm{ni}$ que les familles des disciples apprécient de trouver sur les principaux sites puștimārgìya tout le confort auquel leur classe moyenne urbanisée est désormais habituée. Comme nombre de ces juteuses affaires de "pèlerinages organisés » et d'hôtellerie de luxe sont gérées depuis Ahmadabad, on aurait aimé en savoir davantage sur les relations entre les hommes d'affaires gujaratis et le nationalisme hindou, qui justement monte en puissance au Gujarat dans les années où sa capitale connaît une croissance exponentielle. Cette question reste toutefois en suspens quoique ses enjeux politiques soient importants.

12 Toujours sur la base de son enquête, Richardson montre que dans le milieu des années 1980, ce sont les mêmes réseaux familiaux et de caste, les mêmes capitaux et savoirfaire accumulés en Inde que plusieurs entrepreneurs gujaratis dynamiques vont 
mobiliser pour fonder des temples près des villes américaines où se concentrent les pușt imārgìya : Stone Mountain (Pennsylvanie), Houston (Texas), Addison (Illinois), Phoenix (Arizona), Newington (Connecticut). Grâce à ces temples, où ils observent les mêmes pratiques, le même calendrier et les mêmes grandes fêtes sectaires qu'en Inde, les pușt imārgìy veillent à conserver leur identité religieuse et communautaire: car ils ne recrutent pas de disciples à la différence des cultes de gurus devenus célèbres aux États-Unis à partir des années 1960. En même temps, ils organisent leur vie religieuse conformément aux normes de la société d'accueil. Les temples fonctionnent à l'américaine. Ils œuvrent au service de la communauté gujarati, dépendent de cotisations volontaires et de dons privés et se conforment au système des dénominations, qui repose sur une forte identité confessionnelle et ethnique. Les gosvāmī n'en ont pas la responsabilité ; ils se voient confinés dans un rôle strictement spirituel. Aux États-Unis, ce ne sont plus les disciples qui vont voir les gosvāmī, mais ces derniers qui sont invités pour apporter de la lointaine Inde une certaine légitimité (rien n'est dit des interdits rituels pesant en principe sur le voyage à l'étranger des hindous soucieux de respecter les règles de pureté).

En trouvant sa place dans une organisation sociale pourtant bien différente de celle de son pays d'origine, la secte de Vallabhācārya est devenue une religion américaine, c'està-dire une religion d'immigrants comme les autres religions présentes sur le sol américain. La transplantation des puștimārgìya eux-mêmes ne va pas sans problème. Loin de leur société, ces expatriés rencontrent pour vivre leur hindouisme les mêmes difficultés que leurs coreligionnaires, mais tout au moins depuis le milieu des années 1980 peuvent-ils voir Śrīnāthajī tout près de chez eux. 